\title{
EN BUSCA DEL PERFIL AUSENTE. LA FORMACIÓN JURÍDICA EN MATERIA ACUSATORIA-ADVERSARIAL EN MÉXICO*
}

\author{
Raúl Ruiz Canizales* \\ Luis Eusebio Alberto Avendaño González" \\ Recibido: Agoto 7 de 2015 \\ Aprobado: Octubre 23 de 2015
}

\section{RESUMEN}

A partir de la reforma a la Constitución Política de los Estados Unidos Mexicanos, en junio de 2008, se adopta en nuestro país un sistema acusatorio con tendencia adversarial, el cual representa una transición en la mejora del sistema de justicia. Sin embargo, resulta necesario también que los sectores académicos y estudiantiles instrumenten las mejoras al sistema de enseñanza para enfrentar la baja profesionalización de los operadores del sistema, pero sobre todo de las inercias que ello conlleva en los procesos de formación de profesionales con los perfiles exigibles para este nuevo horizonte.

Palabras claves: Formación jurídica, Perfiles, Sistema acusatorio con tendencia adversarial.

\footnotetext{
* El trabajo es resultado de las actividades del Cuerpo Académico en Formación "Constitucionalismo y Poder Público en México”. La investigación no cuenta con financiamiento y se encuentra vigente a partir de 2014.

** Candidato a Doctor en derecho y profesor de tiempo completo en la Facultad de Derecho de la Universidad Autónoma de Querétaro. Miembro del PROMEP. Correo electrónico: raul.canizales@hotmail.com

*** Doctor en derecho y profesor de tiempo completo en la Facultad de Derecho de la Universidad Autónoma de Querétaro. Miembro del PROMEP y del Sistema Nacional de Investigadores nivel I de CONACYT. Correo electrónico: luis.avendano@hotmail.com
} 


\title{
LOOKING FOR A MISSING PROFILE. LEGAL TRAINING IN ACCUSATORY-ADVERSARIAL AREA IN MEXICO
}

\begin{abstract}
Since the reform of the Constitution of the United Mexican States, in June of 2008, an adversarial system with adversarial trend is adopted, which represents a transition of improving the justice system. However, it is also necessary, that academicians and students adopt the improvements in order to overcome the low professionalization of system operators.
\end{abstract}

Keywords: Legal training, Profiles, Trend adversarial system.

\section{EM BUSCA DO PERFIL AUSENTE. FORMAÇÃO JURÍDICA EM MATÉRIA ACUSATÓRIA - ADVERSARIẢL NO MÉXICO}

\section{RESUMO}

Desde a reforma da Constituição dos Estados Unidos Mexicanos, em Junho de 2008, é adotado um sistema de acusação com tendência adversarial, o que representa uma transição na melhora do sistema de justiça adotado em nosso país. No entanto, também é necessário que os setores acadêmicos e estudantis disponham da renovação no sistema de ensino para enfrentar a baixa profissionalização dos funcionários do sistema, mas principalmente a inércia que ela implica no processo de formação dos profissionais com o perfil exigido neste novo horizonte.

Palavras-chave: Formação jurídica, Perfis, Tendência adversarial do sistema acusatório.

\section{INTRODUCCIÓN}

El sentir general de la sociedad mexicana dejó manifiesto que nuestro sistema de impartición de justicia penal adolecía no solamente de ineficacia, sino también de alta dosis de burocratismo. De esta manera, la procuración e impartición de justicia, lejos de satisfacer las aspiraciones y las necesidades de los sujetos que en ella intervienen, se vio rebasada por prácticas de corrupción e inequidad, lo que provocó que en muchos de los casos las víctimas y acusados padecieran la incertidumbre jurídica e impunidad que la caracterizó. Pero en términos 
generales son muchas más las causas que dieron lugar a la inevitable decadencia del funcionamiento del sistema de justicia penal; por ello no podemos reducirlas a una sola, de lo contrario resultaría a todas luces simplista, o se pecaría de incurrir en un cierto reduccionismo ingenuo. Sin embargo, resulta crucial identificar y reconocer que el mismo marco jurídico en el que éste encontraba su fundamento y su razón de ser, ya no cumple con los fines para los cuales fue diseñado: garantizar el debido proceso legal así como cumplir con los principios que lo conformaban: celeridad, inmediatez, seguridad jurídica, entre otros. Pero insistimos, fue el propio marco jurídico el que contribuyó a su ineficacia, a la generación de un esquema obsoleto que se tradujo, en muchos de los casos, en una clara injusticia para la ciudadanía. De ahí que resultara imperante e impostergable poner sobre la mesa de debate las propuestas sobre las posibles alternativas para corregir, a partir de la acumulación de experiencias, aquellos aspectos sustantivos que no estaban cubriendo las expectativas sociales.

A partir de lo anterior y de la reforma a la Constitución Política de los Estados Unidos Mexicanos, en junio de 2008, se adopta en nuestro país un sistema acusatorio con tendencia adversarial, que a su vez descansa sobre tres ejes o ideas fundamentales: la primera de ellas tiene que ver con la necesidad de servir como marco de respuesta a un conflicto de intereses generado a consecuencia de la comisión de un delito; segundo, que la respuesta que se espera sea bajo la observancia de los principios y garantías de un debido proceso, en el que resalta el derecho a un juicio - en este caso oral- previo; y en tercer lugar promover que sean los sujetos involucrados en el conflicto penal (víctima e inculpado) los que propicien una respuesta consensuada a su controversia, lo que significa una justicia penal consensual-restaurativa, a través de los mecanismos alternos de solución al conflicto jurídico penal. Sin embargo, esta empresa en la que se involucra a todas las entidades federativas del país se antoja más compleja de lo que aparenta, pues se desata un tipo de subsistemas de justicia penal referentes a cada una de ellas.

Si bien es cierto que esta reforma en algunos rubros representa un salto cualitativo y cuantitativo para mejorar el sistema de justicia, también lo es que en otros sectores (académicos y estudiantiles) se generan enormes retos y consecuencias. Un desafío mayúsculo será la instrumentación de las mejoras al sistema de enseñanza para enfrentar la baja profesionalización de los operadores del sistema, pero sobre todo de las inercias que ello conlleva en los procesos de formación de profesionales con los perfiles exigibles para este nuevo horizonte. 
En este sentido, el presente ensayo tiene como propósito describir la relación necesaria entre el sistema acusatorio, y el enfoque argumentativo del derecho. Se trata de una relación emanada de la reforma a la carta magna de los Estados Unidos Mexicanos, en cuya parte esencial subyace el ejercicio de la argumentación como la piedra de toque de los procesos orales.

Para efectos de exposición de la idea central decidimos estructurar este trabajo en tres apartados: el primero, se enfoca a la descripción de la naturaleza y alcance de los juicios orales; en segundo término, nos proponemos describir la relación entre la naturaleza de los juicios orales y el necesario dominio del lenguaje, para en un tercer y último apartado, desarrollar el trinomio juicios orales-dominio del lenguaje argumentación jurídica, en la que esta última se expone como la nueva asignatura alrededor de la cual necesariamente deben girar otras tantas y se traduce, a un mismo tiempo, en la disciplina que justifica la reforma constitucional así como la reestructuración del currículum de cualquier programa de licenciatura en derecho y de los estudios de posgrado. Es decir, se desarrollará la tesis de que es la argumentación jurídica la pieza fundamental y estratégica que justifica cualquier instrumentación de mejoras a los programas curriculares a efecto de generar perfiles acordes con las exigencias derivadas de dicha reforma constitucional.

\section{SISTEMAACUSATORIO. NATURALEZAYALCANCE}

Con la expresión "sistema de juicios orales" se ha construido todo un edificio de significaciones, dentro del cual la estructura la constituye un conjunto de nociones íntimamente relacionadas con tres aspectos fundamentales: primero, la respuesta a una exigencia social que consiste en el diseño de nuevas formas que garanticen una auténtica "impartición pronta y expedita de justicia" tal como actualmente lo marca el texto constitucional; segundo, garantizar el derecho a un debido proceso o juicio (oral); y tercero, la posibilidad de que las partes involucradas formen parte de la solución del conflicto.

La primera de ellas, como mencionamos en la parte introductoria, obedece a una realidad social en la que el propio sistema mexicano de impartición de justicia había quedado rebasado, mientras que las expectativas ciudadanas se acumulaban. Nos referimos al sistema inquisitivo del derecho penal, basado en los procedimientos escritos; de ahí que uno de sus rasgos más distintivos sea la enorme acumulación de expedientes. Pero de esta característica se desprendieron otras no menos 
gravosas, las cuales se puede resumir en las siguientes (Carbonell et. al., 2007, pág. 42):

a) Nunca fue efectivo para perseguir ni mucho menos para capturar a los delincuentes.

b) Generó altos niveles de corrupción e impunidad.

c) No se garantiza de manera fehaciente el respeto a los derechos fundamentales ni de las víctimas ni de los acusados.

d) No contempla un esquema de incentivos para una verdadera y profesional investigación del delito; y

e) Resulta elevadamente costoso y con pobres resultados.

Además de lo anterior, se generó una especie de escepticismo ciudadano para con las instancias judiciales: inhibió la cultura de la denuncia. Pocos eran los delitos que se denunciaban y de estos últimos solo un bajo porcentaje concluía con sentencia condenatoria (92\%). El sentir de la población no era ni es del todo benévolo cuando se refiere a la función tanto del ministerio público como de los jueces. De hecho el espíritu de desconfianza de los ciudadanos mexicanos tiene su raíz en los procesos penales, pero poco a poco permeó el ambiente civilista e incluso hoy en día es el actuar de la propia Suprema Corte de Justicia de la Nación quien ha estado sujeta a la severidad de la crítica por parte de ciertos actores políticos y civiles.

En este sentido, el diseño de un nuevo sistema de impartición de justicia derivó en una reforma a la carta magna, mediante la cual a su vez se diseñaron nuevos esquemas y dinámicas, lo que desencadenó el "trastoque" de las estructuras tradicionales de nuestra familia jurídica, fundamentalmente inscrita en el paradigma del proceso penal concebido como un marco para la legitimación de la sanción estatal o de la violencia legal. A partir del inicio de los trabajos y debates parlamentarios se comenzaron asomar ciertos aires de ligero escepticismo hasta otros tantos de repudio total; como consecuencia de lo anterior, se generó un conjunto de mitos alrededor de aquella iniciativa de reforma. Mencionaremos algunos de los que tratadistas como Enrique Ochoa y Miguel Carbonell (Carbonell et. al., 2008, pág. 239) exponen en una interesante reflexión acerca de lo mismo:

1. Los juicios orales son una imitación del sistema norteamericano / anglosajón.

2. Los juicios orales no van con nuestra propia cultura popular, ni con nuestra tradición jurídica. 
3. Los juicios orales son una política pública de derecha.

4. En los juicios orales vencerá el mejor orador, el demagogo, no quien tenga la razón.

5. Los juicios orales son más costosos.

6. Los juicios orales colapsarán el sistema, pues no habrá tiempo de escuchar cada caso.

7. Los juicios orales solo funcionan para casos menores, pero no servirán para atender los casos de mayor peligrosidad.

De todos estos mitos, nos encargaremos por el momento del segundo para abordar el cuarto en apartado posterior.

En cuanto al segundo de ellos Carbonell y Ochoa desnudan este mito cuando atinadamente esgrimen que, en todo caso, ni el federalismo ni la división de poderes han sido una aportación al mundo jurídico-político de la cultura mexicana. A lo anterior le sumaría el caso de los juicios laborales, los cuales constituyen litigios en los que predomina la oralidad y lo que a su vez ha permitido la fluidez de acuerdos entre las partes. No solo eso, sino que en México se cuenta con precedentes de la oralidad pero ligado a un jurado público, práctica que fue abandonada al final de los años veinte. Este segundo mito tiene que ver con un salto cualitativo mas no cuantitativo, pues, como lo afirmamos, nuestra tradición jurídica se distingue en la forma como se desarrollan los juicios y que son primordialmente escritos; con el adverbio "primordialmente" quiero decir que no todas las áreas del derecho son o tienen en su completud como rasgo distintivo y único "la escritura", es decir, en su más amplio sentido significa que la vía de las actuaciones durante el procedimiento lo constituyen las denominadas "promociones por escrito". El procedimiento laboral ha sido desde su génesis una forma ajena y diferente al desarrollado en los asuntos civiles, mercantiles, penales, etcétera, en el que la oralidad ha sido el denominador común o un rasgo distintivo, además de la conciliación entre las partes. Pero la parte más importante que deseamos destacar tiene que ver con lo mencionado en el primer párrafo de este apartado: que una de las razones impulsoras de la reforma a la Constitución Política de los Estados Unidos Mexicanos tiene que ver con una exigencia social que consiste en el diseño de nuevas formas que garanticen una auténtica "impartición pronta y expedita de justicia" tal como actualmente lo marca el texto constitucional, pero que además sea lo menos costoso posible. Por ello el legislador contempló la posibilidad de que la vía de solución de los conflictos atienda a la naturaleza de los mismos. Esto a su vez marcó la pauta para diseñar lo que Zepeda Lecuona ha denominado "salidas alternas", mismas que se pueden resumir de la siguiente manera: 
a) Principio de oportunidad, implica los casos de delitos menores y no violentos: bajo este supuesto, de manera escrita, el ministerio público mientras no lo impugne el denunciante, envía al archivo los asuntos que juzgue no reúnen los suficientes elementos para realizar una investigación;

b) Justicia alternativa: significa que en casos de conflictos incipientes o "menores" — como se les suele denominar en la jerga jurídica - tales como injurias, golpes que no causen o impliquen lesión, así como algunas modalidades de conflictos familiares;

c) Acuerdos reparatorios: implica los casos de accidentes de tránsito, que constituyen una cuarta parte de los procesos penales;

d) En los casos de delitos no violentos o casos de personas acusadas y que por primera ocasión cometieron un ilícito, se ofrece la posibilidad de optar por la suspensión del procedimiento a prueba, es decir que la persona repare el daño o pague una multa asignada por el juez o se compromete a prestar servicios a la comunidad o incluso se compromete a asistir a pláticas de orientación según la naturaleza del ilícito; pero también puede consistir en otros tratamientos tales como terapia. Incluso se puede comprometer a cumplir cualquier otra condición como el no acercarse a la víctima; en estos supuestos el caso se archiva provisionalmente.

e) Ahora bien, si la persona cumple las condiciones antes mencionadas y además de ello no incurre en acusaciones penales durante determinado lapso, entonces se presenta la posibilidad de que el caso se archive definitivamente.

f) Sin embargo, ¿qué pasa si vuelve a ser acusado? En este supuesto se reactiva el procedimiento anterior, lo que ocasionará que no pueda suspenderse el nuevo caso.

g) Por último, la reforma deja abierta la posibilidad de lo que se ha denominado el "juicio abreviado", que consistente en que todo imputado libre de cualquier presión o coacción y debidamente informado, ante la presencia de evidencia suficiente sobre su responsabilidad — aspecto que queda a consideración del juez-acepte o confiese su participación en los hechos (guilty plea) o simplemente esa confesión haya sido producto de una negociación de tal reconocimiento ( $p l e a$ bargaining) renunciando a presentar pruebas y alegatos 
correspondientes, a efecto de que éste reciba una sanción menos gravosa (Zepeda, 2010, pág. 125).

Todas estas salidas alternas comparten un denominador común: se aplicarán por mecanismos simplificados, accesibles y orales.

En la misma doctrina se aprecia un ambiente de optimismo, además de que las cifras de las experiencias externas han arrojado evidencia empírica de las bondades de estas reformas y sus consecuentes efectos. Cuando mencionamos en algunos párrafos atrás que esta reforma que ahora nos convoca había desencadenado el "trastoque" de las estructuras tradicionales de nuestra familia jurídica (penal), quise decir también con ello que precisamente este conjunto de "salidas externas" son generadoras de una nueva forma de impartir justicia, en la que se presenta la posibilidad de que, como se asentó, las partes en conflicto sean a un mismo tiempo el vínculo de la resolución. Es decir, se abandona un esquema de impartición de justicia compuesta por litigios longevos y costosos, cargados de excesiva burocracia y de un excesivo protagonismo del ministerio público y del juez. A lo anterior se suman los penosos casos de aquellos imputados que después de largas "estancias" en las prisiones preventivas (incluso de hasta 10 años) finalmente reciben una sentencia absolutoria acompañado de un legendario y mítico "usted disculpe". Sobre esto dice Carbonell que “(...) donde se han implantado con éxito los juicios orales ha sido posible descongestionar el trabajo de los tribunales mediante diversas salidas alternativas al juicio. Es decir, las victimas que han sufrido un delito tienen la oportunidad y la asesoría profesional para llegar a un acuerdo con su agresor, a fin de que éste repare el daño que ha causado y se evita recorrer el calvario de un juicio penal. La amigable composición, la mediación y/o el acuerdo reparatorio pueden ser medios idóneos para reparar los daños sufridos y beneficiar a la víctima. Pero también permiten dedicar las energías del sistema judicial a los casos verdaderamente complejos. Un éxito del sistema oral es que la gran mayoría de los casos penales se resuelvan antes de llegar al juicio" (2008, pág. 250). Esas eran y siguen siendo las injusticias de la justicia mexicana.

\section{JUICIOS ORALES Y DOMINIO DEL LENGUAJE}

Se involucran dos aspectos medulares en la reforma a nuestra carta magna: el debido proceso y la oralidad. En la introducción también mencionamos que la respuesta que se espera de esta reforma es la observancia de los 
principios y garantías de un debido proceso, en el que resalta el derecho a un juicio —en este caso oral — previo. Pero ¿qué implican, para efectos de la temática que nos convoca, ambas nociones en un contexto todavía lleno de expectativas? En este capítulo nos abocaremos a describir la oralidad como uno de rasgos más distintivos del nuevo sistema de justicia penal y las necesarias implicaciones a que esto conlleva.

Bajo la expresión "juicios orales" se involucran principalmente dos cosas: la primera de ellas hace alusión a un nuevo modelo de justicia penal, para el que su nombre y apellido sería "sistema acusatorio adversarial", y cuyas características generales ya fueron expuestas. La segunda acepción se refiere a los juicios orales como "un conjunto de instituciones que pretenden lograr una mejora cualitativa y cuantitativa del sistema penal" (2010, pág. 261); también puede ser entendido como un "camino libre y dinámico de diálogo racional para llegar a la verdad y a la justicia, en el cual se exponen argumentaciones opuestas, en las que las hipótesis son objeto de refutación, para sacar a la luz la verdad, superar la duda, y sobre todo, resolver el conflicto que se ha propuesto. Es el escenario por excelencia donde las pruebas se desahogan en mérito al planteamiento metodológico o estratégico de las partes, a fin de fortalecer su versión de los hechos y debilitar la de su contraparte" (Benavente, 2010, pág. 11).

Si se observa con detenimiento, es la segunda definición la que permite acercarse al propósito de este apartado: destacar que la oralidad (llámese verbalidad) se traduce en la vía más importante y el aspecto cualitativo que reviste a una parte fundamental del nuevo proceso penal, al grado tal que la propia reforma constitucional ha dado pauta para colocarla en un pedestal doctrinario.

Ahora bien, cuando se advierte que aquélla implica un ejercicio de comunicación no escrita, lo que se quiere decir con ello es que lleva en su esencia la idea de la verbalidad, es decir, actos de habla en el más amplio de los sentidos. Se trata, pues, de la verbalidad como sinónimo de oralidad; por ello se concluye que ésta "consiste en el predominio de la palabra hablada sobre la escrita, lo cual se traduce en el hecho de que todos los elementos aportados en el juicio son de forma directa y oral, constituyendo éstos el fundamento de la sentencia" (Casanueva, 2008, pág. 78).

Hay que tener presente que el punto medular de los juicios orales reside en que las partes (adversarios) estarán en posibilidad de argumentar y probar sus pretensiones, pero ahora frente a un juez que tendrá la facultad 
de resolver —en atención a esos argumentos esgrimidos verbalmenteel litigio que las convocó. Se trata de un escenario donde emisor y receptor se encuentran en un franco y público enfrentamiento de argumentos, de enunciación de fonemas acompañados de acciones.

Pero es precisamente esta verbalidad la que desata serios retos a los profesionales del derecho, en virtud de que ésta no se presenta como algo dado o acabado sin ninguna otra exigencia necesaria para que su desarrollo sea cabal. Si para el correcto ejercicio de la verbalidad u oralidad bastara con la simple enunciación de ideas (fonemas) por parte del emisor, entonces cualquiera que tuviese la mínima posibilidad de enunciar un par o una cadena de significantes - aun cuando en ellos no se adviertan una concatenación o estructura lógica - se colocaría el supuesto o en el conjunto de los individuos con capacidad de argumentar. Así como el derecho tiene sus "reglas de juego", el lenguaje verbal presupone un conjunto de reglas preestablecidas que se deben satisfacer para poder jugar, conforme a esas reglas, el juego del lenguaje hablado. ¿Cuáles son estas reglas preestablecidas que deben satisfacerse? Como todo acto de habla lleva consigo una intención, esta intención debe estar respaldada por una estructura lógica; esta estructura lógica la ofrece - a su vez y en una primera instancia- el lenguaje debidamente formulado. No basta la simple emisión (enunciación) de una intención, sino que se debe llegar al fundamento de la significación objetiva de cualquier enunciado lingüístico, es decir, que ambas partes compartan significado y significación. A propósito, advierte Dietrich Schwanitz, filólogo alemán, que "la significación objetiva de un símbolo constituye la base de toda objetividad y de toda instrumentalización: desde el martillo hasta la ciencia, pasando por la escritura; gracias al lenguaje, podemos expresar con exactitud nuestros estados anímicos difusos y hacerlos accesibles para nosotros mismos" (Schwanitz, 2002, pág. 412).

La pregunta con que se cerrará el subcapítulo anterior no es para menos, sobre todo si se parte del hecho de que la puesta en acción de esta dinámica (la oralidad) exige a su vez el dominio de otras cualidades tales como el dominio del lenguaje escrito. ¿Por qué? Porque cuando se habla se dice lo que se piensa en el momento, la espontaneidad de los actos de habla domina el juego del lenguaje hablado, es decir de la oralidad (verbalidad). (Olson R. David et. al, 1995, pág. 25).

En este mismo orden, compartimos aquellas tesis que resaltan la primacía del lenguaje como precondición para la correcta argumentación: quien no domina perfectamente el lenguaje y no puede 
expresarse con corrección, es incapaz de pensar correctamente. Pero esto no queda ahí: el dominio del lenguaje advierte un gen que es el del hábito de la lectura, actividad que genera una riqueza lexicográfica y la posibilidad de construir proposiciones gramaticalmente correctas. Un emisor capaz de construir este tipo de proposiciones es capaz de "jugar" con los niveles lógicos de lenguaje, aunque he de aclarar que el simple dominio — por sí solo— de una buena gramática, no genera sistemáticamente una correcta argumentación, pero sí una expresión elemental. Esto tiene directa relación con aquella tesis de Giovanni Sartori (Sartori, 2001, pág. 45) que describe la relación entre el desarrollo de la inteligibilidad con el lenguaje referencial (connotativo) y el lenguaje conceptual. El primero de ellos no refiere ninguna complicación puesto que el vocablo (significante) cuenta con su referente, con un correlativo: el objeto a que se refiere; mientras en el lenguaje conceptual, por su parte, carece de ese objeto, pues estamos en presencia de conceptos abstractos - no visibles - que devienen de procesos mentales y que se traducen en entidades lingüísticas, esto exige de todo sujeto un ejercicio de abstracción más agudo que el que cotidianamente se desarrolla o como diría el propio Sartori, exige una mayor capacidad científico-cognoscitiva, lo que le hace concluir que es este tipo de lenguaje el que contribuye al desarrollo de la inteligibilidad y consecuentemente, al desarrollo de la capacidad de una correcta comunicación.

Lo anterior lleva a otro aspecto fundamental: dado que somos porque tenemos lenguaje, toda racionalidad es connatural a éste, premisa que se enfrenta a la clásica tesis que atribuye esta connaturalidad al hombre (homo) para constituir con ello su carácter esencial. Y esta connaturalidad es lo que hace del homo un homo sapiens sapiens. Se dice que cuando el hombre nombró las cosas, se apoderó del mundo. Pasa del mundo de lo material al mundo real, o si se quiere, al mundo de la realidad. Pasa de ser un testigo mudo de este mundo de lo material para ser el demiurgo de la realidad. Con el lenguaje nace el ser... y la racionalidad.

Es el lenguaje lo que da ese rasgo distintivo, esa peculiaridad. Hay un binomio necesario entre lenguaje y racionalidad puesto que ésta desprende el conjunto de la significación objetiva, pero a su vez no se presenta tampoco como algo dado, sino que se encuentra precisamente inserta en la palabra. Heidegger afirmó que la palabra es la morada del ser; yo por mi parte afirmo que palabra es la morada de la racionalidad. Ser y racionalidad cohabitan en el lenguaje. 
Somos seres lingüísticos, y esta lingüisticidad permite al hombre sacarlo del círculo de la "animalidad", y por tanto, crear ese mundo de segundo orden que es el mundo simbólico constituido de significaciones (objetivas). Este conjunto de significaciones objetivas emitidas a través de la oralidad sólo es tal si advierte en esta práctica un claro dominio del lenguaje, "El dominio del lenguaje impacta de modo directo cualquier ejercicio argumentativo que quiera realizarse, no basta tener un buen argumento, el mejor de los argumentos si se quiere, hay que saberlo expresar de forma adecuada. Para ello, será necesario un conocimiento básico de las reglas que lo gobiernan y que junto con la lógica, darán por resultado una buena argumentación" (Dehesa, 2006, pág. 69).

\section{JUICIOS ORALES Y ARGUMENTACIÓN JURÍDICA}

Actualmente los principales paradigmas del derecho que se perciben en el mundo occidental son los siguientes:

a) El positivista (o paleopositivista para sus detractores);

b) El constitucionalista (o postpositivista)

c) El garantista (uso garantista del derecho);

d) El marxista;

e) El alternativista latinoamericano.

A partir de la reforma a la carta magna de México el paradigma que recobra suma importancia es el constitucionalista que a su vez involucra un enfoque argumentativo. En este último apartado se describirán cuáles son los aspectos medulares (rubros) que éste exige sean abordados o, que se trastocan a partir de ese engranaje (paradigma constitucionalista/enfoque argumentativo), so pena de adolecer de una débil apreciación general del mismo.

\section{ESTADO CONSTITUCIONAL DE DERECHO}

Durante mucho tiempo no se reconoció que el poder del Estado se sujetara a las normas que forman el Derecho de ese Estado; por ejemplo, el "Estado absolutista" en el que las leyes eran dictadas por el monarca y se trataba de un derecho subordinado a la voluntad de quien detentaba el poder del Estado. De esta manera se puede colegir que la plena sumisión del Estado al orden jurídico es un fenómeno de "reciente" aparición: aparece con el surgimiento de la corriente denominada constitucionalismo. Este movimiento da origen a la estructura moderna del Estado de Derecho (Estado burgués de derecho), en la que se 
presenta una nueva versión en la relación poder y derecho, pues aquel es sometido a este último y, normalmente, este derecho es expresado en un conjunto de normas fundamentales (Constitución). En esta nueva expresión todos los componentes del Estado están sujetos al imperio de la Constitución: gobernantes y gobernados deben ajustar su conducta social a las normas contenidas en esa ley suprema. Se trata de la concreción de una tesis clásica del Estado liberal. A la idea de Estado de Derecho se sumó una filosofía que tuvo una fuerte raigambre entre la comunidad de juristas y filósofos: el positivismo.

Aquel binomio se antoja como el encuentro de dos concepciones que terminaron en una codependencia teórica: por un lado el Estado de Derecho requirió una fuerte dosis de poder o de violencia legal, mientras que el positivismo jurídico, por su parte, exigía una alta dosis de formalismo. La condición de validez de las normas sólo dependía de un asunto procedimental y de autoridad. Este paradigma entra en una franca crisis a partir de la segunda mitad del siglo $\mathrm{XX}$ al ser víctima de fuertes embates por parte del naciente paradigma constitucionalista, cuyas rasgos distintivos, en palabras de Manuel Atienza, advierten las siguientes ideas: a) un principio dinámico del sistema jurídico político, que implica una distribución formal del poder entre los diversos órganos estatales; b) un conjunto de derechos fundamentales que limitan o condicionan - en el proceso de producción-el contenido de las normas así como su interpretación y aplicación; c) un conjunto de mecanismos de control de la constitucionalidad de las leyes; pero para satisfacer esta constitucionalidad de las leyes "No basta con la referencia a la autoridad (al órgano competente) y a ciertos procedimientos, sino que se requiere también (siempre) un control en cuanto al contenido"(Atienza, 2006, pág. 17). Por tanto, el paradigma constitucionalista o postpositivista del derecho se presenta como la culminación del Estado de derecho o — diría por mi parte-como la "fase superior" del Estado de derecho.

\subsection{Un nuevo tipo de juez.}

El enfoque argumentativo ha "diseñado" un nuevo tipo de juez que ya nada tiene que ver con aquel de corte formalista que "mecánicamente" obtiene del sistema jurídico la solución incluso para los casos difíciles. Se trata de un juez cuya función, según la concepción austiniana de la Escuela Analítica, basta con que haga un ejercicio de subsunción o "deducción lógica"; pero — como dice el propio Atienza—, desde esta concepción formalista kelseniana se le atribuye a este tipo de juez una función poco lúcida. En el enfoque argumentativo lo que se abandera es 
un tipo de juez en el que se dé cuenta de las peculiaridades del razonamiento jurídico.

La siguiente tabla esquematiza los rasgos de un juez de corte positivista y juez postpositivista:

Tabla 1

\begin{tabular}{lll} 
Rasgos de un juez & \\
\hline & Positivista & Postpositivista \\
\hline $\begin{array}{l}\text { Aplica las normas } \\
\text { neutralmente } \\
\text { (mecánicamente). }\end{array}$ & $\begin{array}{l}\text { No es el que aplica las normas } \\
\text { (reglas) neutralmente, sino } \\
\text { correctamente. }\end{array}$ \\
Rasgos & $\begin{array}{l}\text { Lealtad a las reglas, a } \\
\text { las fuentes explícitas } \\
\text { (como la voluntad del } \\
\text { legislador). }\end{array}$ & $\begin{array}{l}\text { Su lealtad no es para con la voluntad } \\
\text { del legislador, sino con ciertos } \\
\text { valores: lo correcto, lo justo, lo } \\
\text { moutral, apolítico. }\end{array}$ \\
\hline
\end{tabular}

Como se observa, el campo de acción del juez postpositivista no se ubica en una concepción cerrada, estática, sino en una abierta en la que vuelve la vista al sistema social y sus componentes tanto morales, como políticos, económico y culturales. Tiene que garantizar no solo la correcta aplicación de la norma, sino la validez atendiendo al contenido sustantivo.

Otros aspectos que entran en juego y que poco se abordan en la doctrina se pueden describir como sigue:

\subsection{Diseño curricular institucional.}

Se comentó en párrafos anteriores que, si bien es cierto que la oralidad no es una experiencia nueva para el sistema jurídico mexicano, también lo es que la verdadera relevancia de los juicios orales viene tomada de la mano del surgimiento de toda una discursividad en favor del Estado constitucional de derecho. Es decir, aparece en el momento preciso en el que el paradigma positivista $-\mathrm{O}$ paleopositivista - se encuentra en franca crisis o, en el mejor de los casos, de debilitamiento doctrinario y en el que uno de los protagonistas de este enfrentamiento contra el positivismo es, precisamente, el paradigma constitucionalista. Quedó explicado también que uno de sus rasgos más distintivos es la figura de un juez con un papel más dinámico y menos estático; esta dinámica tiene que ver — desde el paradigma constitucionalista— con una aplicación ya 
no "neutral" ni "mecánica" de las leyes, sino con la aplicación correcta de las mismas. Ahora bien, el grado de corrección no se mide con una parafernalia diseñada por las instancias procesales, sino que tiene que ver con el ejercicio de la maximización de los valores de la práctica jurídica, y ésta necesariamente va acompañada de una alta dosis de argumentos que justifiquen racionalmente y guíen las decisiones (interpretaciones) del juez; pero también exige una fuerte dosis de integración de otros dos componentes —además del derecho- de la razón práctica: moral y política. Se trata, pues, de la pretensión de justicia. Esto es en lo que toca al juez. En lo relativo al profesional del derecho, éste no se encuentra exento de la necesidad de argumentar, pues lo hace ante el juez, pero también ante el propio cliente o la contraparte. En cada uno de estos escenarios siempre existe la pretensión de validez de sus argumentos, y el éxito de ésta deviene directamente de su capacidad argumentativa o de exponer argumentos sólidos y bien estructurados. Esto es lo que justifica el rediseño de nuevos programas en las licenciaturas de derecho, momento oportuno para incluir la asignatura denominada "Argumentación jurídica".

Ahora bien, sin el ánimo de que las sugerencias que a continuación se detallan se antojen como simples recetas académicas o de una visión simplista, se propone exponer las siguientes estrategias orientadas a formar cuadros de profesionales del derecho con una amplia capacidad argumentativa y desempeño en cualquiera de las áreas en las que se puede involucrar:

\section{Argumentaciónjurídica.}

En muchas universidades se encuentra bajo la denominación "Argumentación y redacción jurídica", además de ser una asignatura relativamente reciente. Los objetivos de esta materia normalmente se enfocan a las siguientes prioridades: $a$ ) introducir al estudiante en los problemas generales de la argumentación jurídica; $b$ ) que reconozca la importancia de la lógica y de la retórica en el discurso jurídico; $c$ ) que se le proporcionen las herramientas prácticas y técnicas de argumentación jurídica así como las principales posturas contemporáneas de los teóricos de la materia, sobre todo en lo relativo al procedimiento justificatorio del discurso judicial; sin embargo, el diseño del contenido en esta asignatura debe contener - de manera ineludible- los siguientes objetivos: (1) contemplar la sola denominación "Argumentación jurídica", con ello se elimina el vocablo "redacción"; (2) Para una mejor compresión del contenido necesariamente tiene que 
desplazarse al último periodo lectivo; es decir, procurar que el alumno previamente haya abordado los temas que se señalan más adelante en el subapartado c); (3) Los objetivos están enfocados en lo que a continuación se describe a) Mostrar al alumno la relevancia de la argumentación en el Derecho; $b$ ) dar a conocer las distintas teorías y concepciones que se han elaborado sobre la argumentación jurídica; $c$ ) dotarlos - como futuros juristas- de instrumentos teóricoconceptuales adecuados para el análisis de argumentos jurídicos y $d$ ) ejercitarlos en las habilidades necesarias para llevar a cabo un buen uso argumentativo del Derecho. A un mismo tiempo, los propósitos no explícitos de esta disciplina se sugiere enfocarlos principalmente en $a$. Aportar a los estudiantes el instrumental conceptual adecuado para mirar el Derecho no como un todo ya construido que preexiste de forma fija a la labor de los aplicadores e interpretes del Derecho; $b$. que se perciba como una obra en continuo proceso de construcción; $c$. Ver el Derecho como una práctica social, esto es, como un instrumento para la resolución de problemas prácticos.

\section{Gramática y sintaxis (estructura del lenguaje).}

Este rubro se antoja como superficial o demasiado técnico. Y en realidad nada de ello le es propio o característico. En el capítulo dos de este trabajo se expuso la tesis que advertía que "quien no domina perfectamente el lenguaje y no puede expresarse con corrección, es incapaz de pensar correctamente." Se recurrió a ella con la intención de aclarar la importancia que reviste el dominio del lenguaje como una precondición para el desarrollo de la expresión oral. Asimismo, se afirmó que el dominio del lenguaje, de la estructura del lenguaje, no se da por sí solo, sino que exige a su vez el único hábito que posibilita dicho talento: el hábito de la lectura. Constituye un hábito que desata la posibilidad de construir proporciones gramaticalmente correctas (Muñoz, 2008, pág. 21). Por ello se hace énfasis en que si un emisor o parlante es capaz de construir este tipo de proposiciones también lo será de "jugar" con los niveles lógicos de lenguaje. La razón de esto lo constituye el sentido de inteligibilidad que se desarrolla sobre todo con la lectura en la que predomina el lenguaje conceptual, no visible, es decir meras entidades lingüísticas, puesto que el sujeto no solo decodifica sino que además lleva a cabo un proceso de abstracción más agudo que el que exige el lenguaje denotativo, referencial, objetual. De esta manera, si la argumentación es un diálogo en el que un sujeto o emisor presenta una serie de argumentos, con una dosis de razonabilidad y con una pretensión de validez mediante la cual tiende a modificar la conducta del 
receptor o enunciatario a efecto de que éste acepte la tesis (argumento) de aquel, entonces este diálogo necesariamente es mediante lenguaje articulado, (en sus tres funciones principales: representativa, expresiva y señalativa). Pero todo lenguaje articulado debe reunir una mínima estructura que le permita una comunicación coherente, debidamente estructurada que le posibilite el acceso al siguiente nivel de la comunicación: la inferencia lógica. Toda pretensión de validez va tomada de la mano de la inferencia lógica.

Una estrategia extracurricular que puede diseñarse es la conformación de Talleres de lectura, los cuales — sin lugar a dudas - son bastante benéficos, pues tienen como propósito, en una primera instancia, fomentar este hábito y generar con ello aptitudes que le permitan al estudiante mejorar sus condiciones de aprendizaje. Un rubro oportuno para ello sería aquello que en algunas universidades denominan "Literatura y derecho", mediante la cual se abordan obras clásicas y contemporáneas y en cuyo contenido se vislumbren aspectos jurídicos. Existe una literatura amplia que puede servir a los propósitos de esta estrategia: desde novelas rusas hasta latinoamericanas, pasando, obviamente, por las europeas.

La otra estrategia extracurricular son los Cursos de ortografía y redacción, mismos que deben contemplar tres niveles y cada uno de ellos se desarrolle durante un ciclo lectivo. El primer nivel abrazaría exclusivamente aspectos como gramática y ortografía. El segundo se abocaría exclusivamente a la redacción y, por último, el tercer nivel se destina a la comprensión de textos. Como se mencionó anteriormente, nuestra propuesta de la asignatura "Argumentación jurídica" elimina el vocablo "redacción", pues los conocimientos que involucra esta temática no pueden incluirse en un programa de esta naturaleza, sino que se requiere otro tipo de estrategias como estos cursos de ortografía y redacción que se proponen, cuyo contenido gire en rededor de todo lo que se requiere para una expresión escrita elemental. Se trata de mecanismos ad hoc encaminados a subsanar, en lo posible, este tipo de deficiencias que afectan cada vez más no solo a generaciones de estudiantes sino también a muchos miembros del gremio de profesores.

Un esquema que permite explicar la concatenación de elementos directamente relacionados con la redacción y con la argumentación sería el siguiente: 


\begin{tabular}{lll}
\hline \multicolumn{1}{c}{ Redacción } & \multicolumn{1}{c}{ Argumentación } \\
\hline & a) Gramática. & a) Lógica. \\
b) Ortografía. & b) Lógica simbólica. \\
c) Sintaxis. & $\begin{array}{l}\text { c) Lógica proposicional. } \\
\text { d) Conectores lógicos. En una } \\
\text { "subinstancia" de esta área: }\end{array}$ \\
& d) Redacción. & e) Retórica. \\
& e) Estructura de lenguaje. & f) Argumentación. \\
f) Comprensión de textos. & $\begin{array}{l}\text { Lo anterior permite desarrollar } \\
\text { aptitudes para elaborar } \\
\text { razonamientos más sólidos. }\end{array}$ \\
\hline
\end{tabular}

\section{Otras asignaturas.}

Dada la trascendencia de la asignatura "Argumentación jurídica", se requiere que otras de las que componen el mapa curricular de la licenciatura en derecho $-\mathrm{y}$ que tienen relación directa- sean modificadas en sus contenidos con el objetivo de que éstos se perfilen en la misma dirección que aquella. Estas asignaturas son las siguientes y pertenecen al área básica:

\section{Introducción al derecho.}

Esta asignatura debe tener como propósito dejar de ser una simple introducción o caracterización teórica del Derecho, por lo que debe intentar acercar el fenómeno jurídico con la realidad social. Los temas torales que deben abordarse son los siguientes: ¿Qué es el derecho?, La relación entre derecho y normas, entre derecho y moral, derecho y poder, funciones sociales del derecho, las cuestiones relativas a los valores jurídicos (justicia y derechos humanos), derechos y saberes jurídicos, derecho y argumentación, concepciones jurídicas más importantes (iusnaturalismo, positivismo, realismo, marxismo, etcétera).

\section{Métodos y técnicas de investigación jurídica.}

Los temas fundamentales que tenderían a concatenarse con la argumentación jurídica serían, en un primer apartado, la noción y características de la ciencia, su origen y su relación con la filosofía; el origen y ejercicio de la racionalidad en el mundo griego (racionalidad). De igual modo esta materia se antoja como la asignatura oportuna para introducir al alumno en los temas relacionados con el lenguaje, lenguaje 
jurídico, lenguaje interpretado, lenguaje significativo, por lo que también aquí es pertinente contemplar los temas que tengan que ver con la semiótica, semántica jurídica, filosofía analítica y el estructuralismo lingüista e incluso, de gramática elemental. Asimismo se requiere abordar los temas de la ciencia jurídica y su construcción como tal; diferenciar en entre el derecho como ciencia y la ciencia del derecho, luego se deben contemplar temas como la epistemología en general y epistemología del derecho (modelos epistemológicos o metodológicos: iusnaturalismo, positivismo, realismo, marxismo, etcétera).

Otro apartado debe dedicarse a los temas concernientes al método y la metodología, su importancia y trascendencia en la construcción del conocimiento, los métodos aplicables al derecho, etcétera, además de los temas propios de las técnicas de la investigación.

\section{Teoría del Estado.}

Además de los temas clásicos tales como Estado, Estado nación, fines del Estado, sus elementos y teorías que describe esta noción, debe contener una temática que se aboque a explorar la evolución del Estado de derecho al Estado constitucional del Derecho, puesto que este último está directamente relacionado con el enfoque argumentativo además de ser la culminación del paradigma positivista.

\section{Teoría del derecho.}

Se requiere explorar los conceptos jurídicos fundamentales (normas regulativas - principios y reglas-, normas constitutivas - reglas que confieren poder y reglas puramente constitutivas-, enunciados valorativos y definiciones, entre otros). Es decir una teoría adecuada (actualizada) de los enunciados jurídicos que permita dotar al alumno de los conceptos jurídicos básicos necesarios para la mejor comprensión de la teoría de la argumentación contemporánea y para que los futuros profesionistas puedan actuar con sentido en el contexto de un Estado constitucional.

\section{Filosofía del derecho.}

Una primera parte necesariamente tiene que abordarse a la Historia de la filosofía del derecho, que a su vez se puede subdividir en historia de la filosofía del derecho hecha por filósofos (de Aristóteles a Kant) e historia de la filosofía del derecho hecha por juristas (desde el Escuela Histórica 
hasta el Constitucionalismo: de Dworkin y otros). Una segunda parte consistiría en otros temas contemporáneos que inciden en la discusión del campo jurídico: bioética, informática, teoría de la justicia (objeción de conciencia, desobediencia civil, entre otros), derecho y globalización, pluralismo jurídico, multiculturalismo, derecho como sistema abierto, etcétera. En un apartado especial debe contemplarse todo lo relacionado con la filosofía analítica o filosofía del lenguaje: su nacimiento, evolución así como la importancia que reviste para el derecho concebido como lenguaje.

Figura 1.

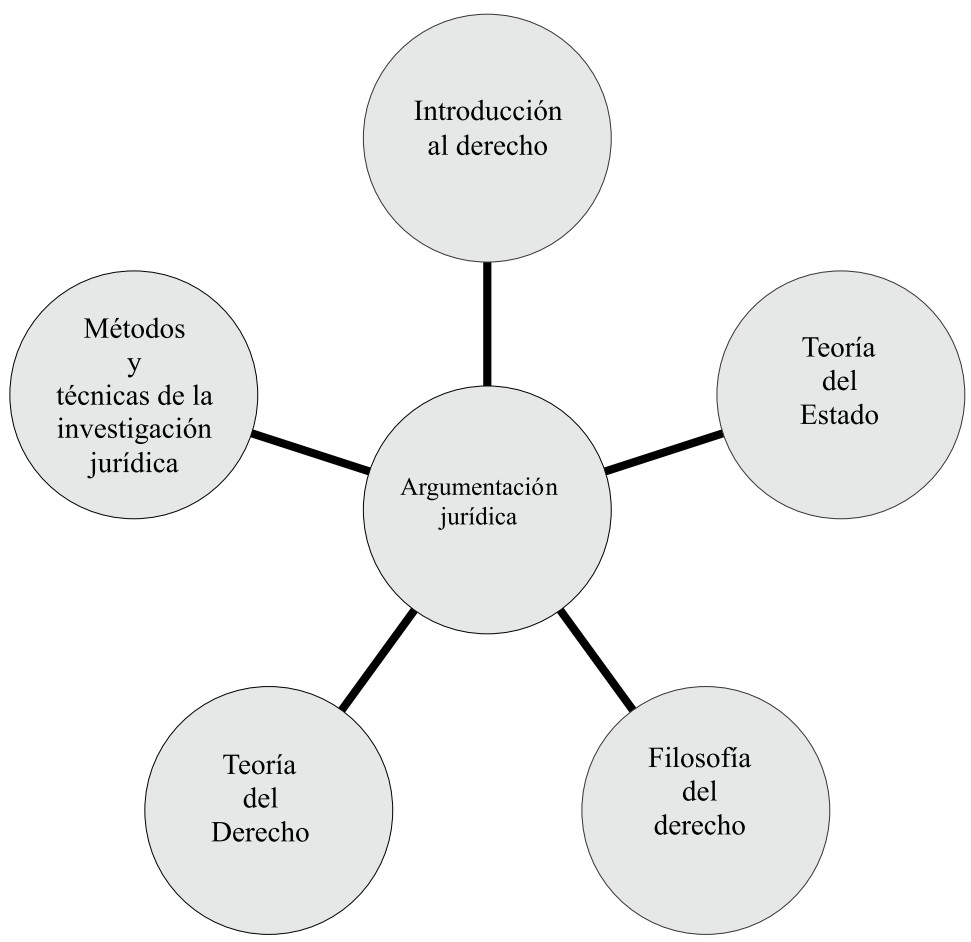

Es decir, lo que se debe buscar es que el estudiante previamente cuente con un conjunto de elementos conceptuales proporcionados por las asignaturas anteriormente descritas; lo esto con la finalidad de cubrir los conocimientos necesarios requeridos para un mejor aprendizaje de lo que es la argumentación jurídica. Todo ello permitiría formar cuadros de futuros profesionales del derecho capaces de desenvolverse con aptitudes sólidas en el ejercicio del derecho ya sea en el ámbito del litigio, de la asesoría, del servicio público o de la enseñanza, pero sobre todo con una alta competitividad. 


\section{CONCLUSIONES}

Estamos en el umbral de una nueva práctica de justicia penal en la que el abandono del viejo paradigma es casi un hecho. Resta a la comunidad jurídica y la propia sociedad mexicana esperar los frutos de este ambicioso proyecto que tiene como uno de los propósitos generales transformar radicalmente las caducas vías de acceso al debido proceso.

Lo anterior exige de la sociedad política la implementación de estrategias finamente diseñadas a fin de lograr una instrumentación gradual pero segura, sin cortapisas. En la comunidad académica, por su parte, recae la responsabilidad más apremiante y delicada, pues de éstas egresarán los futuros profesionales del derecho con el perfil mínimo que requieren para desempeñarse en el campo de acción; este perfil mínimo abraza un conjunto ineludible de cualidades que ya fueron descritas en este trabajo. La renuencia de muchos actores académicos, sociales y políticos para la implementación de este nuevo esquema de administración de justicia ha evidenciado un tipo de mentalidad que aún permea en nuestra nación: el miedo a los grandes cambios estructurales. Tanto en los defensores como en los detractores del sistema acusatorio adversarial existen "argumentos" sólidos para remar a favor o en contra de esta tendencia, según sea el caso; pero si los "pro" y los "contra" se colocan en el fiel de la balanza, los aspectos favorables para su implementación resultan constituir la mayoría. Algunos de estas razones también se describieron en este documento.

Ala sociedad civil le resta, en una primera instancia, depositar un voto de confianza en este ambicioso proyecto, pues es en ella en donde se escucharon las primeras y perennes expresiones de reclamo producto de un hartazgo y de la secuela de nefastas contradicciones entre el espíritu del texto legal y lo que en la cotidianeidad experimentaron y sufrieron miles de ciudadanos. En una segunda instancia, le corresponde seguir en función de críticos del desempeño judicial y ministerial, pues sería ingenuo pensar que este nuevo esquema viene como algo ya dado en su conformación y mecánica; en el mejor de los casos se trata de un sistema en el que la misma práctica lo hará perfectible, pues como toda institución política y jurídica, requieren la instrumentación inteligente de cada una de sus piezas y en las que los actores (sociedad, Estado y academia) desarrollen todo su potencial en aras de no deformar el espíritu que dio origen y que impulsó esta empresa. 


\section{REFERENCIAS BIBLIOGRÁFICAS}

Abelardo, J., \& Hernández, F. (2010). Argumentación Jurídica. México D.F.: editorial Oxford.

Atienza, M. (2006). El derecho como argumentación, Barcelona: editorial Ariel.

Benavente, H et al. (2009). Derecho procesal penal aplicado. Con juicio oral, derechos y principios constitucionales, Serie Nuevo Sistema Procesal Acusatorio. México D.F.: Flores Editor y Distribuidor.

Benavente, H. (2010). Estrategias para el desahogo de la prueba en el juicio oral. . México D.F.: Flores Editor y Distribuidor.

Carbonell, M., \& Ochoa, E. (2007). "Juicios orales y debido proceso legal: una propuesta de reforma”. Iter Criminis. No. 11.

Carbonell, M., \& Ochoa, E. (2008). "Ocho mitos y realidades sobre los juicios orales". En El sistema de justicia penal en México: retos y perspectivas, edición a cargo de la Suprema Corte de Justicia de la Nación, D. F., México.

Carbonell, M., \& Ochoa, E., (2008). ¿Qué son y para qué sirven los juicios orales. ( $2^{\mathrm{a}}$ ed.). México D.F.: Porrúa-UNAM.

Casanueva, S. (2008). Juicio oral. Teoría y práctica ( $3^{\mathrm{a}}$ ed.). México D.F.: Editorial Porrúa.

Castillo, J., Lujan M., \& Zavaleta R. (2006). Razonamiento judicial. Interpretación, argumentación y motivación de las resoluciones judiciales, (2 ${ }^{\mathrm{a}}$ ed.). Lima: Ara Editores.

Dehesa, G.(2006). "Los conectores lógicos del lenguaje, elementos indispensables para la argumentación jurídica". En Memoria del Seminario de Argumentación Jurídica, Suprema Corte de Justicia de la Nación, D. F., México.

Galindo, E. (2008). Argumentación jurídica. Técnicas de argumentación del abogado y del juez.México D.F.: Porrúa.

González, S. (2004). Código semiótico y teorías del derecho. México: Fontamara, colección Doctrina Jurídica Contemporánea. 
Hoyos, A. (2006). Debido proceso y democracia. México D.F.: Porrúa.

Múñoz, C. (2008). Lexicología jurídica. México D.F.: editorial Oxford.

Olson, D., \& Torrance, N. (Comp.). (1995). Cultura escrita y oralidad. Barcelona: editorial Gedisa.

Pastrana, J. \& Benavente, H. (2009). El juicio oral penal. Técnicas y estrategias de litigación oral, Serie Nuevo Sistema Acusatorio Penal. México D.F.: Flores Editor y Distribuidor.

Sartori, G. (2001). Homo videns. La sociedad teledirigida (2 ${ }^{\mathrm{a}}$ ed.). México D.F.: editorial Taurus.

Schwanitz, D. (2002). La cultura. Todo lo que hay que sabe., Madrid: Editorial Taurus.

Zepeda, G. La reforma constitucional en materia penal de junio de 2008. Claroscuros de una oportunidad histórica para transformar el sistema penal mexicano, Análisis Plural, México, No. 3. Recuperado de http://portal.iteso.mx/portal/page/portal/Dependencias/Rectoria/Dependencias/Direc cion_General_Academica/Dependencias/Depto_de_estudios_sociopoliticos_y_jurid icos/Programas_academicos/Derecho/Noticias/08-07La\%20reforma2008ITESO.doc 